\title{
O livro didático de inglês como LE: uma análise das atividades de produção oral
}

\author{
Givanildo Silva Santos \\ Universidade Estadual de Santa Cruz \\ givantos@ hotmail.com \\ Joara Martin Bergsleithner \\ Universidade de Brasília \\ joaramb@ hotmail.com
}

\section{Resumo}

Esta pesquisa, quantitativa, teve por objetivo analisar as Atividades de Produção Oral (APOs) que compõem duas coleções de Livro Didático (LD) de inglês como LE para o ensino médio da rede pública no Brasil, English for all e Globetrekker, a fim de verificar os tipos de APOs que as duas coleções apresentavam e qual grau de comunicabilidade as duas coleções possuíam, no sentido de perceber qual delas poderia oferecer um melhor desenvolvimento da habilidade oral. A metodologia utilizada encontra-se nos moldes da pesquisa quantitativa, utilizando regra de três simples e cálculos de porcentagem. O suporte teórico fundamenta-se em autores como Littlewood (2004); Chang e Lee (2011); Lajolo (1996); Coracine (1999); Bergsleithner (2009); Penny (1991); Ellis (2003); Nunan (1989) entre outros. Os resultados apontaram que a coleção English for all apresenta um grau de comunicabilidade maior do que a coleção Globetrekker, revelando que a primeira coleção configura-se como mais comunicativa por propor APO com o foco da instrução na forma que se caracterizaram mais como tarefas comunicativas do que exercícios mecanizados e que conduzem os aprendizes a usar a língua com mais atenção ao significado, podendo possibilitar aos aprendizes um melhor desenvolvimento da habilidade oral.

Palavras-chave: Livro didático. Língua estrangeira. Língua inglesa. Habilidade oral. Atividades de Produção Oral.

\section{Abstract}

This quantitative research aimed to analyze oral production activities of two English textbook collections of EFL in Public High School in Brazil, English 
for all and Globetrekker, in order to verify the types of OPA that both collections presented and the degree of communicability they had in order to verify which one could provide a better development of the oral skill. The methodology adopted was quantitative, using rule of three and calculation of percentage. The theoretical support is based on some authors such as Littlewood (2004); Chang; Lee (2011); Lajolo (1996); Coracine (1999); Bergsleithner (2009); Penny (1991); Ellis (2003); Nunan (1989) among others. The results showed that one of the collections has a higher degree of communicability than the other, revealing that this collection seems to be more communicative because it proposes OPA with the main focus of instruction on form, that is more like characterized as communicative tasks than mechanized exercises which can lead learners to use the language with more attention to the meaning without neglecting aspects of language forms, allowing learners to be able to better develop the oral skill.

Keywords: Textbook. Foreign language. English language. Oral skill. Oral production activities.

\section{Introdução}

No cenário atual do ensino/aprendizagem de línguas, tornou-se comum a ideia de que aprender uma LE significa tão somente poder "falar" essa língua. É muito comum ouvirmos no nosso dia a dia a pergunta: "Você fala inglês?" ou mesmo a afirmação: "Eu sei falar inglês", como se o ato de "falar (speaking)" assumisse um status privilegiado em relação às outras habilidades linguísticas, isto é, ouvir (listening), ler (reading) e escrever (writing). Desse modo, parece haver uma preocupação maior de muitos aprendizes com a habilidade oral no processo de aprendizagem de uma LE (BERGSLEITHNER, 2009).

A preocupação em poder falar uma LE não atinge somente os aprendizes, pois o processo de ensino de língua inglesa (doravante LI) em sala de aula sempre foi questionado por professores devido a diversos fatores-problemas, tais como poucas aulas de LE por semana, falta de material didático e, muitas vezes, falta de oportunidades para os aprendizes vivenciarem a língua-alvo (CLAUDINO, 2005; LAJOLO, 1996; SOUZA, 2012, XAVIER; URIO, 2006). Dentre os fatores que fazem parte do ensino de LI nas escolas públicas do Brasil, está o livro didático público de inglês (LD doravante), que tem 
ganhado certa atenção nos últimos anos do Ministério da Educação (MEC) e do Programa Nacional do Livro Didático (PNLD), os quais estabelecem critérios para a inserção e a seleção dos LDs nas escolas públicas do Brasil.

Os LDs de LI como LE para o segmento do ensino médio são compostos de uma série de conteúdos e atividades que poderão auxiliar os aprendizes no desenvolvimento da competência da LI. As atividades presentes nos LDs geralmente são elaboradas para trabalhar as quatro habilidades linguísticas mencionadas anteriormente, sejam elas integradas sejam isoladas.

Nesse sentido, esta pesquisa teve por objetivo analisar as Atividades de Produção Oral (APOs) que compõem duas coleções de Livro Didático (LD) de inglês como LE para o ensino médio da rede pública no Brasil, English for all e Globetrekker, a fim de verificar os tipos de APOs que as duas coleções apresentavam e qual grau de comunicabilidade as duas coleções possuíam/apresentavam no sentido de perceber qual delas poderia oferecer um melhor desenvolvimento da habilidade oral por meio das APOs.

A importância deste estudo reside no fato de se analisar um LD que possui um valor significativo na rede pública de ensino e, muitas vezes, pode ser a fonte mais acessível para o aprendiz ter contato com uma língua estrangeira, especificamente neste estudo, a LI. Além disso, esta pesquisa torna-se relevante porque há poucos estudos sobre a questão do desenvolvimento de atividades voltadas para a habilidade oral em LI como LE em LD destinados aos alunos da rede pública do ensino médio. ${ }^{1}$

\section{0 livro didático}

Entende-se que didático é aquilo que tem como função básica viabilizar a instrução, ou seja, "próprio para instruir", abrangendo um "conjunto de meios, técnicas e procedimentos que concorrem para a

\footnotetext{
${ }^{1}$ Considera-se, a partir dessa informação, a inserção do LD público de inglês para o ensino médio ser um fato muito recente, no ano de 2012, conforme aponta o PNLD (2012).
} 
apropriação, por um sujeito determinado, de elementos novos de todas as ordens" (MARTINEZ, 2009, p. 9).

Conforme Lajolo (1996, p. 4), “didático, então, é o livro que vai ser utilizado em aulas e cursos, que provavelmente foi escrito, editado, vendido e comprado tendo em vista essa utilização escolar e sistemática". Lima (2011, p. 124) corrobora com essa ideia quando afirma que "o LD é importante, pois, muitas vezes, define o conteúdo do ano letivo, o planejamento das aulas, as propostas de avaliação e os métodos e técnicas a serem utilizadas pelo professor".

Para Xavier e Souza (2008), o LD funciona como um guia para o professor que utiliza esse instrumento em sua atuação e dos alunos em sala de aula. Seguindo essa linha de pensamento, Coracini (1999) traça uma discussão acerca das críticas em torno do livro didático, principalmente com o surgimento da abordagem comunicativa, revelando que depois do advento da abordagem comunicativa o LD passou a ser criticado por muitos professores de LE, pois ele acabava limitando o trabalho do professor.

Considerando tais questões, vale pontuar que este, antes de chegar às escolas, passa por um processo de avaliação realizada pelo Ministério da Educação (MEC), que também é responsável pela aprovação dos LDs que serão distribuídos para as escolas públicas. A distribuição é realizada pelo Programa Nacional do Livro Didático (PNLD), o qual tem como objetivo principal auxiliar o trabalho pedagógico dos professores da rede pública de ensino (PNLD, 2012).

Nesse contexto, as obras selecionadas deveriam atender a uma série de preceitos estabelecidos pelo edital PNLD (2012). Alguns pesquisadores, como, por exemplo, Xavier e Urio (2006), argumentam que o LD de inglês bem como outros livros de LE podem influenciar os professores no conteúdo que será ensinado, nas atividades que serão propostas, nas habilidades linguísticas apresentadas e nos objetivos de aprendizagem. Em outras palavras, no processo de ensino e aprendizagem, o LD em sala de aula pode se caracterizar como uma ferramenta que prediz o quê e como o professor pode trabalhar em sala de aula, principalmente quando for explorar as habilidades de uma LE, como, por exemplo, a habilidade oral em LI. 


\section{A habilidade oral em LI}

De acordo com os PCN (2000), a principal meta para o ensino de LEs no ensino médio é a comunicação oral e escrita, concebendo a comunicação como uma ferramenta fundamental no mundo moderno, visando à formação profissional, acadêmica ou pessoal.

Percebe-se, dessa forma, que no processo de ensino/aprendizagem de uma LE é esperado que o aprendiz esteja apto a falar na língua-alvo, isto é, a produzir oralmente essa língua a fim de usá-la nas mais diversas situações de comunicação. Nessa linha de pensamento, Chaney (1998 apud KAYI, 2012, p. 13) afirma que a produção oral é "o processo de construir e compartilhar significados através do uso de símbolos verbais e não verbais, em uma variedade de contextos". ${ }^{2}$ Infere-se, dessa, maneira, que o uso da habilidade oral está intimamente ligado à comunicação, isto é, à troca de mensagens entre indivíduos, que pode ser realizada nos mais diversos contextos.

Hausmann e Martinelli (2008) salientam que falar uma LE não significa memorizar exaustivamente um conjunto de frases ou regras gramaticais, mas que:

Falar é saber emitir opiniões, fazer e responder perguntas, ter a capacidade de emitir todos os sons da língua e ter maturidade verbal e léxica para escolher como, quanto, o que e a quem dizer a ideia que se quer expressar (p. 40).

Para Mota, Bergsleithner e Weissheimer (2011), de todas as capacidades de nossa espécie, a fala é considerada a habilidade mais complexa. Essa complexidade, segundo as autoras, envolve vários aspectos, tais como os cognitivos, revelando que no processo de aprendizagem há diferenças cognitivas individuais entre os aprendizes: enquanto uns desempenham a fala com mais eficácia, outros apresentam mais dificuldade ao produzir oralmente a segunda língua (L2).

\footnotetext{
2 "The process of building and sharing meaning through the use of verbal and non-verbal symbols, in a variety of contexts" (CHANEY, 1998 apud KAYI, 2012, p. 13).
} 
A habilidade oral, assim, assume um valor significativo no processo de ensino/aprendizagem de LE, como enfatiza Penny (1991): "De todas as quatro habilidades (ouvir, falar, ler e escrever), falar parece intuitivamente a mais importante: as pessoas que sabem uma língua são referidas como 'falantes' dessa língua" (p. 120). ${ }^{3}$

Nesse sentido, Mota (2010) salienta que, na última década, tem-se percebido um aumento do interesse em se estudar a produção da fala em LE ou segunda língua (L2). A autora (op. cit.) acrescenta ainda que a produção oral é considerada uma das principais linhas de investigação dos processos em habilidades de L2. Portanto, infere-se que a habilidade oral envolva o uso da língua com troca de significados, troca de mensagens e ideias, por meio da produção oral em diferentes contextos.

\section{Tarefas versus exercícios}

No campo de ensino/aprendizagem de LE, vários teóricos trazem conceitos do que seja "tarefa". Conforme Bygate, Skehan e Swain (2001), a tarefa é "uma atividade que requer ao aprendiz fazer o uso da língua, com ênfase no significado, para alcançar um objetivo"4 (p. 11). Na concepção de Ellis (2003), a tarefa apresenta-se como um plano de trabalho no qual os aprendizes devem usar a língua pragmaticamente, a fim de atingir um resultado. Já para Scaramucci (1995), a tarefa refere-se a uma atividade de ensino diferente das utilizadas nos moldes tradicionais, pois tem um propósito comunicativo e se assemelha ao uso da linguagem presente na vida real.

Nesse sentido, é relevante discutir o que difere uma "tarefa" de "exercício". Conforme Ellis (2003), as tarefas trazem o uso da língua com foco principal no sentido, enquanto os exercícios trazem foco

3 "Of all the four skills (listening, speaking, reading and writing), speaking seemsintuitively the most important: people who know a language are referred to a 'speakers' of that language [...]" (PENNY, 1991, p. 120).

4 "A task is an activity which requires learners to use language, with emphasis on meaning, to attain an objective" (BYGATE, M.; SKEHAN, P.; SWAIN, M., 2001, p. 11). 
principal nas formas. Nessa linha de pensamento, Branden (2006) também traça uma discussão em relação às diferenças entre tarefas e exercícios. Segundo o autor (op. cit.),

As tarefas diferem dos exercícios no sentido de que os aprendizes não têm que provar que eles sabem perfeitamente como aplicar um procedimento específico ou podem (re)produzir fatos de conhecimento (p. 103-104). ${ }^{5}$

Dentro desse mesmo conceito, Nunan (1989) afirma que uma tarefa comunicativa é entendida como uma parte do trabalho realizado em sala de aula, no qual os alunos compreendem, manipulam, produzem e interagem na língua-alvo com o foco principal no significado. Assim, as tarefas constituem uma inovação para o ensino/aprendizagem de línguas, pois seu foco está no significado e não nas formas gramaticais, isto é, elas envolvem principalmente aspectos relacionados ao significado, à comunicação autêntica.

\section{O diagrama de Littlewood e as atividades de aprendizagem: o modelo teórico adotado para este estudo}

Primeiramente, é válido discorrer, brevemente, sobre os tipos de instrução que se fazem presentes no processo de ensino/aprendizagem de uma LE, pois esses estão intimamente ligados ao diagrama estabelecido por Littlewood (2004).

Long e Robinson (1998) apresentam três tipos de instrução: foco no significado (focus on meaning), o qual está voltado para a comunicação sem se preocupar com as formas utilizadas para veicular a informação, foco nas formas (focus on forms), no qual a ênfase está voltada para as estruturas linguísticas, e o foco na forma (focus on form), no qual, segundo Ellis (2003), os aprendizes dão atenção à forma para compreender e produzir mensagens.

Nesse contexto, Littlewood (2004), em seus estudos conduzidos por meio da Abordagem Baseada em Tarefas, esboçou um

\footnotetext{
5 "Tasks differ from exercises in the sense that learners do not have to prove that they perfectly know how to apply a specific procedure or can (re)produce particular facts of knowledge" (BRANDEN, 2006, p. 103-104).
} 
diagrama que mostra um continuum, ${ }^{6}$ que começa com o foco nas formas e termina com o foco no significado, sendo que entre um e outro se pode considerar o foco na forma, sendo este o tipo de instrução que também se faz presente na Abordagem Baseada em Tarefas.

Dessa forma, Littlewood (2004) apresenta o diagrama a seguir, classificando cinco seções que mostram vários tipos de atividades de aprendizagem: (1) aprendizagem não comunicativa, (2) prática précomunicativa da língua, (3) prática comunicativa da língua, (4) comunicação estruturada e (5) comunicação autêntica, como mostra a Tabela 1.

Por meio do diagrama, Littlewood (2004) demonstra que, a partir da prática comunicativa da língua (communicative language practice) em direção ao lado direito do diagrama, estabelece-se o que se considera como tarefas, como propõe Elis (2003). Movendo-se para o lado esquerdo do diagrama, a partir da aprendizagem prática précomunicativa da língua (pre-communicative language practice), observam-se os tipos de aprendizagem, tendo por base o foco nas formas. Em outras palavras, a aprendizagem não comunicativa e a prática pré-comunicativa da língua estão voltadas para o foco nas formas, enquanto a prática comunicativa da língua, a comunicação estruturada e a comunicação autêntica estão ligadas ao foco na forma, isto é, o que prevalece nesse tipo de instrução é o trabalho com o significado, mas sem desprezar as formas gramaticais, porém estas são imprevisíveis.

Com base na Tabela 1, a aprendizagem não comunicativa caracteriza-se com um forte foco nas formas. Em outras palavras, as atividades desse tipo envolvem principalmente aspectos gramaticais descontextualizados. Essa categoria inclui exercícios de substituição, exercícios gramaticais descontextualizados e exercícios de pronúncia, por exemplo (LITTLEWOOD, 2004, p. 322).

\footnotetext{
${ }^{6} \mathrm{O}$ termo em latim continuum será preservado aqui para não descaracterizar o diagrama estabelecido por Littlewood, mas não se diferencia da concepção da palavra em português "contínuo".
} 
Tabela 1. O continuum de foco nas formas para o foco no significado

\begin{tabular}{|c|c|c|c|c|}
\hline Foco nas formas & & $\longleftarrow$ & $\rightarrow$ & $\begin{array}{l}\text { Foco no } \\
\text { significado }\end{array}$ \\
\hline $\begin{array}{l}\text { Aprendizagem } \\
\text { não-comunicativa }\end{array}$ & $\begin{array}{l}\text { Prática pré- } \\
\text { comunicativa da } \\
\text { língua }\end{array}$ & $\begin{array}{l}\text { Prática } \\
\text { comunicativa da } \\
\text { língua }\end{array}$ & $\begin{array}{l}\text { Comunicação } \\
\text { estruturada }\end{array}$ & $\begin{array}{l}\text { Comunicação } \\
\text { autêntica }\end{array}$ \\
\hline $\begin{array}{l}\text { Foca-se nas } \\
\text { estruturas da } \\
\text { língua, como elas } \\
\text { são formadas e o } \\
\text { que significam, p. } \\
\text { ex. exercícios de } \\
\text { substituição, } \\
\text { 'descoberta' e } \\
\text { atividades de } \\
\text { conscientização }\end{array}$ & $\begin{array}{l}\text { Pratica-se a língua } \\
\text { alguma atenção ao } \\
\text { significado, mas } \\
\text { sem comunicar } \\
\text { novas mensagens } \\
\text { para outros, p. ex. } \\
\text { a prática de } \\
\text { pergunta-e- } \\
\text { resposta }\end{array}$ & $\begin{array}{l}\text { Pratica-se a língua } \\
\text { ensinada } \\
\text { previamente em } \\
\text { um contexto no } \\
\text { qual comunica-se } \\
\text { novas informações, } \\
\text { p. ex. atividades de } \\
\text { lacuna de } \\
\text { informação ou } \\
\text { perguntas } \\
\text { 'personalizadas' }\end{array}$ & $\begin{array}{l}\text { Usa-se a língua } \\
\text { para se comunicar } \\
\text { em situações que } \\
\text { evocam a língua } \\
\text { ensinada } \\
\text { previamente, mas } \\
\text { com } \\
\text { imprevisibilidade, } \\
\text { p. ex. role play } \\
\text { (encenação) } \\
\text { estruturada e } \\
\text { resolução de } \\
\text { problema simples }\end{array}$ & $\begin{array}{l}\text { Usa-se a língua } \\
\text { para se comunicar } \\
\text { em situações nas } \\
\text { quais os } \\
\text { significados são } \\
\text { imprevisíveis, p. } \\
\text { ex. role play } \\
\text { (encenação) } \\
\text { criativa e } \\
\text { conversas }\end{array}$ \\
\hline 'Exercicios' & $\longleftarrow$ & (Ellis) & $\longrightarrow$ & 'Tarefas' \\
\hline 'Ativando tarefas' & 4 & (Estaire e Zanon) & $\longrightarrow$ & $\begin{array}{c}\text { 'Tarefas } \\
\text { comunicativas' }\end{array}$ \\
\hline
\end{tabular}

Fonte: LITTLEWOOD, 2004, p. 322 
A prática pré-comunicativa da língua também enfatiza as características estruturais da língua, mas conduz ao significado. Littlewood (2004) classifica a terceira categoria como prática comunicativa da língua, na qual os aprendizes praticam aspectos da língua previamente ensinados em um contexto no qual há a comunicação de novas mensagens.

A quarta categoria, nomeada por Littlewood (2004) como comunicação estruturada, tem como foco principal a comunicação da mensagem. A última categoria encontra-se no lado direito do continuum e é denominada de comunicação autêntica, em que o foco principal está na comunicação de mensagens e as formas da língua são praticamente imprevisíveis.

\section{Metodologia}

Esta pesquisa caracteriza-se como quantitativa e teve por objetivo analisar as APOs de duas coleções de LD de inglês como LE a fim de verificar como essas atividades são caracterizadas nas unidades do livro e que nível de comunicabilidade elas apresentam.

Quatro perguntas de pesquisa nortearam este estudo: (1) que tipos de Atividades de Produção Oral (APOs) são apresentadas nas duas coleções ?; (2) o foco das Atividades de Produção Oral propostas pelas duas coleções está na forma, nas formas ou no significado?; (3) qual das duas coleções apresenta um maior/menor grau de comunicabilidade, considerando-se a tabela indicada por Littlewood (2004) aplicada ao sistema de pontuação de Chang e Lee (2011); (4) qual das duas coleções poderia contribuir mais para o desenvolvimento da habilidade oral em língua inglesa?

O desenvolvimento da pesquisa parte do interesse em se analisar o LD público de inglês como LE para o ensino médio. É preciso sublinhar que o PNLD (2012) incluiu no ano de 2012 um total de sete coleções para o ensino/aprendizagem de inglês como LE nas escolas públicas do Brasil. No entanto, para esta pesquisa interessavam somente as coleções que apresentavam seções que ofereciam as Atividades de Produção Oral, uma vez que este é o foco principal do estudo. Dessa forma, as únicas coleções relevantes para a pesquisa foram: English for All (AUN; MORAES; SANSANOVICZ, 2010) e 
Globetrekker (COSTA, 2010), constituindo, portanto, o corpus da pesquisa.

Levando-se em consideração a proposta desta pesquisa, foram analisadas apenas as APOs, isto é, as atividades desenvolvidas para se trabalhar a produção oral. Assim, restringiu-se a análise das seções Communicative activity, da coleção English for all, e a seção Speak your mind, da coleção Globetrekker, uma vez que essas seções apresentam atividades para se trabalhar com a produção oral.

\subsection{Procedimento da coleta de dados}

O procedimento para a coleta de dados iniciou-se por separar as duas coleções de LD de inglês para o ensino médio que ofereciam APOs. Cada coleção apresenta três volumes e traz unidades que apresentam diferentes seções que têm por objetivo trabalhar as diferentes habilidades linguísticas em LI (falar, ouvir, ler e escrever). Uma vez identificadas as seções, partiu-se para a contagem das APOs nos três volumes de cada coleção. A Tabela 1 mostra o número de APOs encontradas nos volumes das coleções English for all (doravante coleção A) e Globetrekker (doravante coleção B), bem como o total de APOs em cada coleção.

Tabela 2. Total de Atividades de Produção Oral (APOs) nas duas coleções

\begin{tabular}{ccc}
\hline Livro didático & Coleção A & Coleção B \\
\hline Volume 1 & 10 & 24 \\
Volume 2 & 10 & 24 \\
Volume 3 & 10 & 24 \\
\hline Total & 30 & 72 \\
\hline \hline
\end{tabular}

O número total de APOs encontrado na coleção A foi trinta. A coleção B apresentou um total de 72 APOs.

\subsection{Procedimentos para análise dos dados}

A análise das APOs tem como referência o continuum, proposto por Littlewood (2004), o qual apresenta um diagrama que traz no extremo esquerdo o foco nas formas, e no extremo direito, o foco no 
significado, como demonstrado na Figura 1. O diagrama de Littlewood (2004) descreve um continuum de atividades menos comunicativas para mais comunicativas, caracterizando-se as do primeiro tipo mais como exercícios mecanizados, enquanto as atividades que se enquadram no extremo direito do diagrama são mais comunicativas, portanto, tarefas.

Dessa forma, a classificação estabelecida por Littlewood (2004) possibilitou separar as atividades de aprendizagem em cinco tipos, a saber: aprendizagem não comunicativa (Tipo 1), prática précomunicativa da língua (Tipo 2), prática comunicativa da língua (Tipo 3), comunicação estruturada (Tipo 4) e comunicação autêntica (Tipo $5)$.

Para medir o nível de comunicabilidade das APOs nos dois volumes, tem-se como referência principal um sistema estabelecido por Chang e Lee (2011), que transformaram o diagrama de Littlewood (2004) em um sistema de pontuação. Chang e Lee (2011) criaram um sistema de pontuação no qual todas as atividades de aprendizagem receberiam uma pontuação de acordo com sua proposta comunicativa. Dessa forma, a pontuação das atividades varia de uma pontuação mínima de um ponto a uma pontuação máxima de cinco pontos.

De acordo com esse sistema de pontuação, as atividades do Tipo 1 (aprendizagem não comunicativa) receberiam um ponto, pois são consideradas menos comunicativas; as atividades do Tipo 2 (prática pré-comunicativa da língua) receberiam dois pontos; as do Tipo 3 (prática comunicativa da língua) receberiam três pontos; as do Tipo 4 (comunicação estruturada), quatro pontos; e, por último, as do Tipo 5 (comunicação autêntica), cinco pontos, sendo estas, portanto, as mais comunicativas.

Para medir o grau de comunicabilidade nas duas coleções, considerou-se que todas as APOs dos volumes deveriam ser do Tipo 5 (comunicação autêntica). Assim, a pontuação ideal de comunicabilidade seria cinco vezes o número total de APOs presentes nos três volumes de cada coleção. A pontuação real de comunicabilidade é calculada considerando-se o tipo da atividade vezes o ponto atribuído a ela mesma. Para encontrar o grau de comunicabilidade, dividiu-se a pontuação real total de comunicabilidade pela pontuação ideal, conforme pode ser visualizado a seguir: 
Givanildo Santos; Joara Bergsleithner

Grau de comunicabilidade $=$ Pontuação real de comunicabilidade (Tipo $1 \times 1+$ Tipo $2 \times 2+$ Tipo $3 \times 3+$ Tipo $4 \times 4+$ Tipo $5 x 5$ ) / Pontuação ideal (5 $x$ número total de atividades) (CHANG; LEE, 2011, p. 152). ${ }^{7}$

\section{Resultados}

\subsection{Porcentagem de APOs nas duas coleções}

A Tabela 3 mostra a porcentagem dos tipos de APOs nas duas coleções, abrangendo todos os três volumes de cada coleção. Por meio dessa tabela é possível perceber que a coleção A concentra a maior parte das APOs dos tipos 3 (prática comunicativa da língua - Figura 2) e 4 (comunicação estruturada - Figura 2). Por sua vez, a coleção B apresenta uma maior porcentagem das APOs dos tipos 2 (prática pré-comunicativa da língua - Figura 3) e 4 (comunicação estruturada - Figura 4).

Tabela 3. Porcentagem dos tipos de Atividades de Produção Oral (APOs) nas duas coleções

\begin{tabular}{ccc}
\hline Atividades $^{\mathbf{8}}$ & Coleção A & Coleção B \\
\hline Tipo 1 & $6,6 \%$ & $12,5 \%$ \\
Tipo 2 & $6,6 \%$ & $31,9 \%$ \\
Tipo 3 & $40,0 \%$ & $19,4 \%$ \\
Tipo 4 & $40,0 \%$ & $27,7 \%$ \\
Tipo 5 & $6,6 \%$ & $8,3 \%$ \\
\hline \hline
\end{tabular}

\footnotetext{
7"Degree of communicativeness $=$ communicativeness scores $/(5 \times$ the total number of activities).communicativeness scores $=$ Type $1 \times 1+$ Type $2 \times 2+$ Type $3 \times 3+$ Type $4 \times 4+$ Type $5 \times 5$ " (CHANG; LEE, 2011, p. 152).
} 


\section{COMMUNICATIVE ACTIVITY}

Ask your partners about his/her birthday and about his/her family members' birthdays and fill in the chart.

Example: When is your sister's birthday?

When is your father's birthday?

\begin{tabular}{|l|l|}
\hline \multicolumn{1}{|c|}{ Partner's name / birthday } & Family member / birthday \\
\hline Paula $-09 / 30$ & Mother $-03 / 25$, sister $-12 / 05$ \\
\hline & \\
\hline & \\
\hline & \\
\hline & \\
\hline & \\
\hline & \\
\hline
\end{tabular}

Figura 1. Exemplo de APO do Tipo 3 da coleção A (Fonte: AUN et al. English for all, v. 1, 2010)

\section{COMMUNICATIVE ACTIVITY}

Ask your partner to think of an actor, an actress or a singer that he/she likes very much. Then ask him/her: "What does he/she look like?". Listen to your partner's description and try to guess who he/she is talking about.

Figura 2. Exemplo de APO do Tipo 4 da coleção A (Fonte: AUN; MORAES; SANSANOVICZ, English for all, v. 3, 2010, p. 14) 


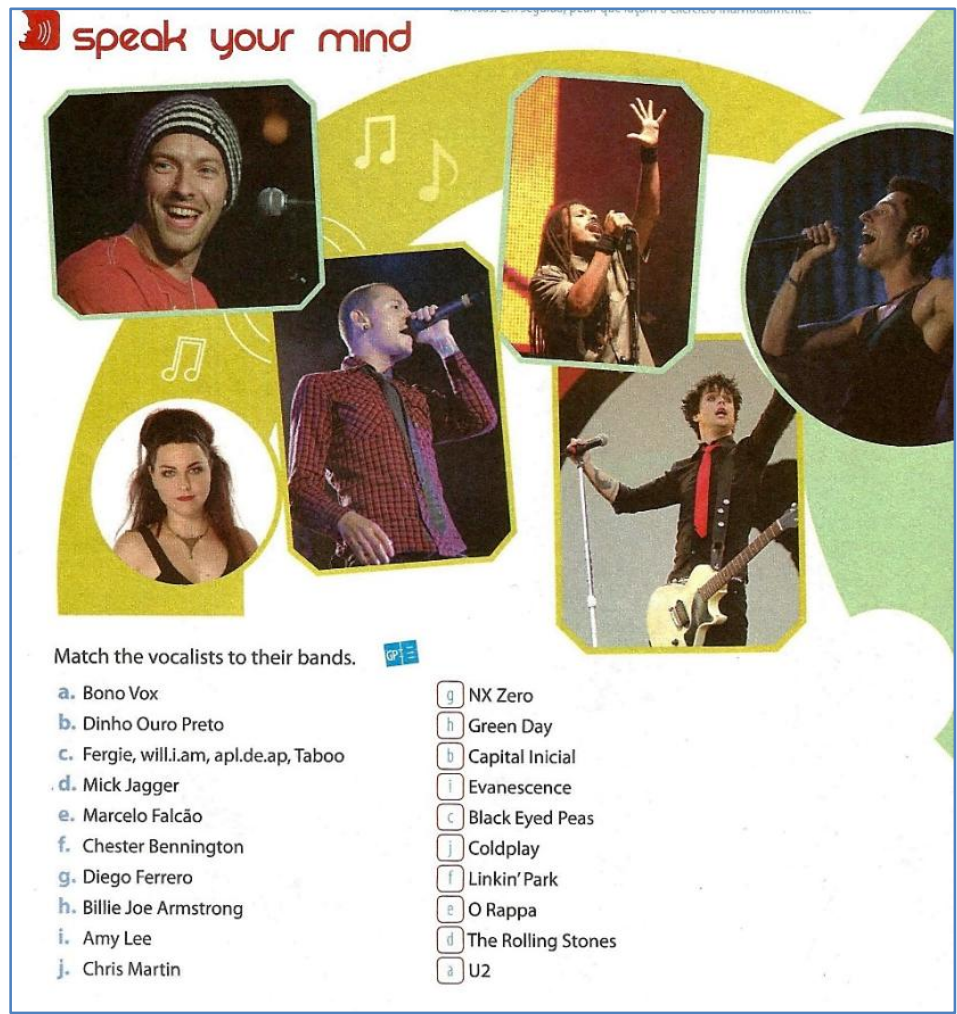

Figura 3. Exemplo de APO do Tipo 2 da coleção B (Fonte: COSTA, Globetrekker, v. 2, 2010, p. 36)

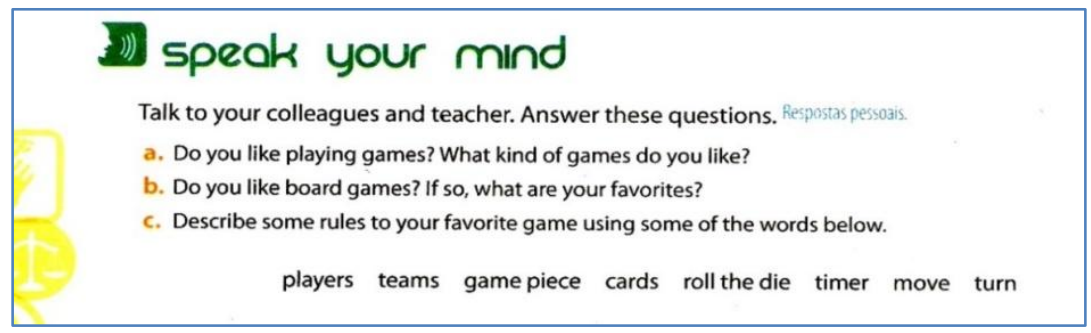

Figura 4. Exemplo de APO do Tipo 4 da coleção B (Fonte: COSTA, Globetrekker, v. 3, 2010, p. 110) 


\subsection{Grau de comunicabilidade}

Esta subseção revela o grau de comunicabilidade nas duas coleções.

A Tabela 4 mostra que a coleção A (English for all) apresenta um grau de comunicabilidade de 0.54 , enquanto a coleção B (Globetrekker) apresenta 0.50. Assim, a coleção A revela um grau de comunicabilidade maior que a coleção $\mathrm{B}$, trazendo em seus volumes APOs mais comunicativas.

Tabela 4. Grau de comunicabilidade nas coleções A e B

Coleção A Coleção B

$0,54 \quad 0,50$

\section{Discussão dos resultados}

Em relação à pergunta de pesquisa 1 deste estudo - que tipos de Atividades de Produção Oral (APOs) são apresentados nas duas coleções? -, os resultados revelaram que as duas coleções, coleção A (English for all) e coleção B (Globetrekker), apresentam os cinco tipos de APOs com base na classificação de Littlewood (2004): Tipo 1 aprendizagem não comunicativa; Tipo 2 - prática pré-comunicativa da língua; Tipo 3 - prática comunicativa da língua; Tipo 4 - comunicação estruturada e Tipo 5 - comunicação autêntica. Esse aspecto revela que ambas as coleções propõem APOs que podem influenciar em grande ou pequena escala o desenvolvimento da habilidade oral dos aprendizes de LI como LE.

A coleção A (English for all) propõe principalmente APOs do Tipo 3 (prática comunicativa da língua). Por meio do continuum, é possível dizer que há uma forte presença de atividades com o foco na forma, isto é, atividades que envolvem aspectos relacionados ao significado, mas também envolvem aspectos gramaticais. Nesse sentido, há uma tendência dessa coleção em propor APOs que conduzem os aprendizes a se envolverem em tarefas que exigem uma 
gama previsível de linguagem, mas transmitem novas informações ao executá-las (LITTLEWOOD, 2004).

A coleção B (Globetrekker), por sua vez, apresenta, predominantemente, APOs do Tipo 2 (prática pré-comunicativa da língua). No entanto, uma porcentagem significativa de APOs do Tipo 4 (comunicação estruturada) também foi encontrada, apontando que pode haver uma preocupação dessa coleção em não direcionar o desenvolvimento da habilidade oral com uma preocupação excessiva com a gramática.

Levando-se em consideração a segunda pergunta de pesquisa o foco das Atividades de Produção Oral propostas pelas duas coleções está na forma, nas formas ou no significado? - verifica-se que a coleção A propõe em grande proporção APOs do Tipo 3 (prática comunicativa da língua). Dessa forma, por essa coleção trazer mais atividades do Tipo 3, é possível perceber que a instrução de ensino que mais influencia essa coleção é o foco na forma. Isto é, as APOs que compõem essa coleção procuram engajar os aprendizes em processo cognitivos, utilizando a forma para compreender e produzir mensagens comunicativas (ELLIS, 2003).

Ao considerar o continuum do diagrama de Littlewood (2004), percebe-se que a maioria das APOs presentes na coleção A se enquadram numa posição em que as formas linguísticas não são o principal foco das atividades. Ao contrário, dá-se uma atenção maior às atividades que poderiam ser chamadas de tarefas em detrimento de atividades que se configurariam mais como exercícios mecanizados, pois as APOs do Tipo 3 possibilitam criar um ambiente no qual os aprendizes podem experimentar a linguagem. Isto é, podem participar da produção da língua de maneira mais ativa por meio da troca de significados (BRANDEN, 2006).

A coleção B revela uma grande concentração de APOs do Tipo 2 (prática pré-comunicativa da língua), mas também apresenta uma porcentagem considerável de APOs do Tipo 4 (comunicação estruturada). No primeiro caso, pode-se inferir que essa coleção ainda atribui certa importância aos aspectos formais da língua. Dentro do continuum, essas APOs caracterizam-se mais como exercícios mecanizados do que tarefas, pois a maioria das APOs do Tipo 2 leva os aprendizes a praticarem a língua (em vez de produzirem) com pouca 
atenção ao significado, sem transmitir ou compartilhar novas informações (LITTLEWOOD, 2004).

No que se refere à terceira pergunta de pesquisa - qual das duas coleções apresenta um maior/menor grau de comunicabilidade, considerando-se a tabela indicada por Littlewood (2004) aplicada ao sistema de pontuação de Chang e Lee (2011)? -, verificou-se que o grau de comunicabilidade da coleção A é superior ao da coleção B. Assim, é possível dizer que a coleção A revela-se mais comunicativa do que a coleção $\mathrm{B}$, pois propõe uma gama de APOs distribuídas de diferentes formas nos volumes que a compõem, concentrando a maior parte delas no Tipo 3. Além disso, mesmo não apresentando uma grande concentração de APOs do Tipo 5, mais comunicativas, a coleção A propõe uma série de APOs que obteve uma pontuação razoavelmente alta por apresentar, em sua grande maioria, APOs do Tipo 3, de acordo com a classificação e proposta. Isso revela que a coleção não prioriza as formas linguísticas, mas propõe atividades comunicativas que têm como objetivo final a comunicação.

A grande concentração das APOs dos Tipos 3 e 4, prática comunicativa da língua e comunicação estruturada, respectivamente, na coleção A atribui a esta um caráter mais comunicativo. Isso não significa dizer que a coleção B não traz APOs comunicativas, mas por concentrar muitas APOs dos Tipos 1 e 2, compromete o desenvolvimento da habilidade oral em LE, considerando-se que, para ser mais comunicativo, o LD deve propor APOs que se configurem mais como tarefas do que exercícios mecanizados. Nessa perspectiva, a presença de tarefas comunicativas torna-se um aspecto relevante para a produção oral em LE.

Dizer que a coleção A é mais comunicativa do que a coleção B significa dizer que esta coleção propõe APOs que levam os aprendizes a fazer o uso da língua sem priorizar o foco nos aspectos formais da língua. Além disso, as APOs mais comunicativas dão oportunidade aos aprendizes de compartilhar respostas, fazer comparações com colegas, interagindo e praticando a negociação de significados (LONG, 1998).

Para responder à quarta e última pergunta da pesquisa - qual das duas coleções poderia contribuir mais para o desenvolvimento da habilidade oral em língua inglesa? -, consideram-se a seguir os resultados obtidos e a discussão tecida anteriormente. Assim, considera-se que a coleção $\mathrm{A}$, por apresentar mais atividades que 
conduzem ao significado do que a coleção B, e, além disso, por revelar um maior grau de comunicabilidade nas atividades, pode contribuir mais para o desenvolvimento da habilidade oral em LI, uma vez que as APOs que compõem essa coleção trazem em si características que podem ser consideradas tarefas, as quais, no contexto de ensino/aprendizagem de línguas, exigem dos aprendizes uma atenção maior ao significado utilizando seus próprios recursos linguísticos, isto é, utilizando seu conhecimento prévio, vocabulário aprendido e expressões para se expressar, comparar, classificar, dar opiniões usando a língua-alvo (ELLIS, 2003).

O maior grau de comunicabilidade encontrado na coleção A permite inferir que esta coleção pode oferecer aos aprendizes a oportunidade de desenvolver melhor a habilidade oral no processo de ensino/aprendizagem de LE, pois ao estarem envolvidos com os tipos de APOs que se caracterizam mais como tarefas, os aprendizes poderão fazer o uso da língua-alvo, trocando informações, por meio de discussões, que fazem parte do processo de falar uma língua, podendo, assim, emitir opiniões, elaborar e responder a perguntas e, por fim, fazer o uso da língua, considerando quando, onde e a quem se expressar (HAUSMANN; MARTINELLI, 2008).

Por se tratar de APOs do tipo prática comunicativa da língua, que envolve uma troca de significados, a interação e o surgimento de novas informações entre os aprendizes, pode-se considerar que esse tipo de tarefas requer maior elaboração/configuração do que APOs de aprendizagem não comunicativa, por exemplo, pois a habilidade oral é uma das habilidades mais difíceis de se trabalhar, uma vez que ela envolve a produção da fala durante o processo de ensino/aprendizagem de uma LE, corroborando, assim, a afirmação de Bergsleithner (2009).

Diante dos resultados e das discussões tecidas anteriormente, pode-se considerar que a coleção A, pelas razões explanadas anteriormente, poderia oferecer uma maior possibilidade para os aprendizes obterem um melhor desenvolvimento da habilidade oral, por meio do trabalho com as APOs da prática comunicativa da língua propostas por essa coleção. Essas APOs, concebidas como tarefas, podem estimular os aprendizes a produzir mais a língua-alvo, a fim de obterem um resultado significativo no processo de aprendizagem de inglês como LE. 


\section{Considerações finais}

Esta pesquisa se propôs a analisar Atividades de Produção Oral (APOs) que compõem duas coleções de LD de inglês como LE inseridas atualmente no cenário da escola pública nacional por meio do PNLD (2012) - English for all e Globetrekker -, tendo como meta principal verificar os tipos de APOs que compõem as duas coleções e qual é o grau de comunicabilidade as duas coleções a fim de verificar qual delas poderia contribuir para um melhor desenvolvimento da habilidade oral em LI como LE.

Os resultados encontrados sugerem que a coleção English for all, em virtude dos tipos de APOs que a compõem, poderia ser considerada a coleção propícia aos aprendizes para um maior desenvolvimento da habilidade oral em LI como LE, por trazer em sua composição APOs mais elaboradas, mais consistentes do ponto de vista da troca de significados e compartilhamento de informações bem como resolução de problemas e discussões, conduzindo os aprendizes a um desenvolvimento da habilidade oral de forma significativa.

Ao conceber que o LD tem o papel de oferecer oportunidades aos aprendizes, por meio de suas atividades, para fazer uso da língua que pretendem aprender, é indispensável que esse LD proponha atividades que levem os aprendizes a desenvolver a habilidade oral para a comunicação. E isso deve ocorrer por meio da negociação de significados e da conscientização do uso da língua em determinados contextos, de modo a levá-los a evitar práticas de itens específicos e estruturas da língua sem nenhum propósito comunicativo.

Por fim, os resultados obtidos neste estudo podem contribuir para o ensino/aprendizagem da LI como LE à medida que se percebeu como as APOs têm sido configuradas e propostas em alguns LDs públicos do Brasil. No entanto, é relevante que pesquisas destinadas a analisar materiais didáticos e pesquisas que discutam a habilidade oral sejam fomentadas no cenário nacional, pois os LDs exercem forte influência no ensino/aprendizagem de línguas, e muitas vezes eles são a única forma de acesso a uma LE para muitos aprendizes, comprometendo, assim, o desenvolvimento do desempenho oral dos aprendizes durante o processo de aprendizagem da LE alvo. 
Givanildo Santos; Joara Bergsleithner

\section{Referências}

BERGSLEITHNER, Joara M. Linguagem oral e aspectos cognitivos em Linguística Aplicada: ensino/aprendizagem de L2/LE através de tarefas. Revista Língua \& Literatura FW, v. 11, n. 17, p. 113-124, dez. 2009.

Atenção e memória de trabalho na produção oral em L2. In: BERGSLEITNER, Joara M; WEISSHEIMER, Janaína; MOTA, Mailce B (Org.). Produção oral em LE: múltiplas perspectivas. São Paulo: Pontes Editores, 2011. p. 21-46.

BRANDEN, Kris V.. Task-Based language education: from theory to practice. Cambridge University Press, 2006.

BRASIL. Ministério da Educação. Secretaria de Educação Média e Tecnológica. Parâmetros Curriculares Nacionais (Ensino Médio). Brasília: MEC, 2000. Disponível em: < http://portal.mec.gov.br/seb/arquivos/pdf/blegais.pdf>. Acesso em: 15 de janeiro de 2012 .

BYGATE, Martin; SKEHAN, Peter; SWAIN, Carol M. (Org.). Researching pedagogic tasks second language learning, teaching and testing. Applied Linguistics and Language Study, London: Longman, 2001.

CLAUDINO, Barthyra. C. V de A. Investigando o LD de língua inglesa: imagens de 2005. Dissertação (Mestrado) - Universidade Federal da Paraíba, João Pessoa, 2005. Disponível em: < http://www.dominiopublico.gov.br/download/texto/cp123852.pd f>. Acesso em: 10 de fevereiro de 2012.

CHANG, Y.; LEE, L. An analysis of speaking activities designs of Junior-High-School English textbooks used in Taiwan and China. National Pingtung University of Education, 2011. 
CORACINI, Maria J R F. Interpretação, autoria e legitimação do livro didático: língua materna e língua estrangeira. Campinas: Pontes, 1999.

ELLIS, Rod. Task-based language learning and teaching. Oxford: Oxford University Press, 2003.

HAUSMANN, E. P.; MARTINELLI, D. R. Falar inglês é difícil? Speaking English: is it difficult? Linguagens: Revista de Letras, Artes e Comunicação. Blumenau, v. 2, n. 1, p. 36 -41, jan./abr. 2008.

KAYI, Hayriye. Teaching speaking: activities to promote speaking in second language. The Internet TESL Journal, vol. XII, n. 11. Disponível em: <http://iteslj.org/Techniques/KayiTeachingSpeaking.html>. Acesso em: 20 de junho de 2012.

LAJOLO, Marisa. Livro didático: um (quase) manual de usuário. Em aberto: livro didático e qualidade de ensino. Brasília, MEC, ano 16, n. 69, jan./mar. 1996.

LIMA, Diógenes C.. (Org.). Ensino e aprendizagem de língua inglesa: conversas com especialistas. 1. ed. São Paulo: Parábola Editorial, 2011.

LITTLEWOOD, William. The task-based approach: some questions and suggestions. ELT Journal, v. 58, n. 4, p. 319-326, 2004.

LONG, Michael; ROBINSON, Peter. Focus on form: theory, research and practice. In: DOUGHTY, Catherine; WILLIAMS, Jessica. Focus on form in classroom second language acquisition. Cambridge: Cambridge University Press, 1998. p. 15-41.

MARTINEZ, Pierre. Didática de línguas estrangeiras. São Paulo: Parábola Editorial, 2009.

MOTA, Mailce B. Interlanguage development and L2 speech production: how do they relate? Psycholinguistics: scientific and technological challenges. SCLIAR-CABRAL, Leonor (Ed.). Porto Alegre: Edipucrs, 2010. p. 220-227. 
MOTA, Mailce B; BERGSLEITHNER, Joara M; WEISSHEIMER, Janaína. Situando a pesquisa sobre produção oral em LE. Produção oral em LE: múltiplas perspectivas. BERGSLEITHNER, Joara M; WEISSHEIMER, Janaína; MOTA, Mailce B (Org.). São Paulo: Pontas, 2011 (Coleção Novas perspectivas em Linguística Aplicada, v. 19).

NUNAN, David. Designing tasks for the communicative classroom. Cambridge: CUP, 1989.

PRAHBU, Nagore S. Second language pedagogy. Oxford: Oxford University, 1987.

PROGRAMA NACIONAL DO LIVRO DIDÁTICO NO BRASIL. Disponível em: $<$ http://portal.mec.gov.br/index.php?option=com_content $\&$ view=articl e\&id=12391\&Itemid=668> . Acesso em: 13 de janeiro de 2012 .

PENNY, Ur. A course in language teaching: practice and theory. Cambridge: Cambridge University Press, 1991.

SCARAMUCCI, Matilde V. R. O papel do léxico na compreensão em leitura em língua estrangeira: foco no produto e no processo. Campinas, Universidade Estadual de Campinas. Tese de doutorado, 1995.

SOUZA, Ricardo A de. A língua na cultura brasileira e na política educacional: um estranho caso de alienação. In: LIMA, Diógenes Cândido de. (Org.). Ensino e aprendizagem de língua inglesa: conversas com especialistas. São Paulo: Parábola Editorial, 2012. p. 133-146.

WILLIS, Jane. A framework for task-based learning. London: Longman, 1996.

XAVIER, Rosely P; SOUZA, Daniele T. O que os alunos pensam sobre o livro didático de inglês? - What do learners think about the 
O livro didático de inglês como LE...

english text book? Trabalhos em Linguística Aplicada, Campinas, v. 47, n. 1, p. 65-89, jan./jun. 2008.

XAVIER, Rosely P; URIO, Everlaine D. W.. O professor e o livro didático: que relação é essa? Trabalhos em Linguística Aplicada, v. 45, n. 1, p. 29-54, 2006.

\section{Coleções analisadas}

AUN, Eliana; MOARES, Maria C P.; SANSANOVICZ. Neuza B. English for all. v. 1, 2, 3. Ensino médio. 1. São Paulo: Saraiva, 2010.

COSTA, Marcelo B. Globetrekker - Inglês para o ensino médio. v. 1, 2, 3. 2. ed. São Paulo: Macmillan, 2010.

Submetido em: 28/09/2014 Aceito em: 11/03/2015

Title: English as a foreign language textbooks: an analysis of speaking activities 